\title{
Effects of short-term memory contents on short-and long-term memory searches*
}

\author{
RICHARD C. MOHS, KEITH T. WESCOURT \\ and \\ RICHARD C. ATKINSONं \\ Stanford University, Stanford, California 94305
}

\begin{abstract}
The Ss memorized a long-term set (LT set) of 20 words before participating in a recognition memory test. On each trial Ss were given a new short-term set (ST set) of from one to four words or one to four digits. The Ss gave a positive response to a test item that was a member of either the ST or the LT set and gave a negative response to a test item not in either set; both words and digits were used as test stimuli. The results indicated that reaction time (RT) to positive test items from the ST set was an increasing function of the size of the ST set; the same was also true for negative responses to test digits when the ST set was composed of digits. RT to other test stimuli, however, did not depend on ST set size. These results are consistent with the view that Ss access long-term memory (LTM) and short-term memory (STM) simultaneously rather than sequentially. The results also showed that Ss responded more quickly to test items from the LT set when the ST set contained digits than when it contained words. Negative test items that were words, however, were rejected more slowly when the ST set contained digits than when it contained words. These results suggest that the search of LTM was affected by the contents of STM.
\end{abstract}

Studies of search processes in short-term memory (STM) and long-term memory (LTM) have revealed differences in the way information is retrieved from these two stores. Sternberg (1969) has presented results from recognition memory experiments in which Ss decided whether a test item (probe) was a member of a positive set of from one to six items. Reaction time (RT) in these experiments was a linear increasing function of the number of items in the set to be searched, and slopes for positive and negative response functions were equal. Sternberg obtained similar results, using both a fixed positive set and a positive set that was varied on each trial, suggesting that the same memory system was being scanned in both cases. Since the positive sets used in these experiments were small and the retention interval (at least for the varied set procedure) was short, it is unlikely that these items were stored in LTM when the test item was presented. Sternberg's RT functions, then, seem to represent times necessary to scan for information in STM.

A modified version of the Sternberg paradigm was used by Juola, Fischler, Wood, and Atkinson (1971) to study search processes in LTM. They used groups of Ss who memorized lists of 10,18 , or 26 words prior to being tested in a recognition memory task. This procedure was similar to Sternberg's (1969) fixed set procedure, except that Juola et al used much larger positive sets and used words rather than digits as stimuli. To insure that the positive set was represented only in LTM at the time of the test, Ss were required to count backward before the test probe was presented. Like

\footnotetext{
*This research was supported by a grant from the National Institute of Mental Health (MH21747).

$\leftarrow$ Requests for reprints should be sent to Professor R. C. Atkinson, Department of Psychology. Stanford University. Stanford. California 94305 .
}

Sternberg, Juola et al found that RT increased linearly with the number of items to be searched. The slopes of the functions relating RT to the number of items in the positive set, however, were about $5.0 \mathrm{msec}$, a value considerably smaller than the $38-\mathrm{msec}$ slope reported by Sternberg. This result suggests that information in LTM is searched faster than information in STM and that different processes may be involved in the two searches.

In an experiment that required Ss to search both STM and LTM, Wescourt and Atkinson (1973) investigated how STM and LTM search processes interact when these stores are simultaneously active. Their Ss were given a recognition memory test in which the positive set consisted of a fixed long-term set (LT set) of 30 words and a varied short-term set (ST set) of from zero to four words. At the start of each trial, the $\mathrm{S}$ was given a new ST set and then presented with a test word. The S was to give a positive response to a word from either the current ST set or the LT set and a negative response to a word not in either of the sets. RT to positive items in STM increased with ST set size, but ST set size had no effect on RT to either negative items or positive items in the LT set. This result is consistent with the view that $\mathrm{Ss}$ searched STM and LTM simultaneously rather than sequentially.

The present experiment investigated the effects of both the number and the type of items in STM on search processes in a task that required the simultaneous activation of both STM and LTM. Ss memorized an LT set of 20 words before the start of the experiment: at the beginning of each trial in the experiment, they were given a new ST set of from one to four words or one to four digits: then they were given a word or a digit test stimulus. The Ss gave a positive response to test items from the LT set or the current ST set: they gave a negative response to distractor items. which included 
digits not in the current ST set and words not in the LT set or the current ST set.

The experiment served two purposes. First, it provided a further test of the hypothesis that STM and LTM are searched simultaneously rather than sequentially. By providing RT data from tasks requiring similar LTM searches while the contents of STM varied (words or digits), the experiment also tested the hypothesis that the search of LTM is affected by the STM search.

\section{METHOD}

\section{Subjects}

Eighteen female students at Stanford University served as Ss. Each $S$ participated in one training session and two experimental sessions; they received $\$ 2$ for each session.

\section{Stimuli}

Words for LT sets, ST sets, and distractor test stimuli were taken from the Thorndike-Lorge word list. All words were four to eight letters in length, had two syllables, and had frequency counts of more than 20 per million. Distractor words and words in ST sets were each used on only a single trial of the entire experiment; once a word had been used as a nember of an ST set or as a negative test item, it was never presented again to that S. Digits used in ST sets and as distractors were selected from a table of random numbers, subject to the following constraints: (a) only the digits 1-9 (not 0 ) were used, and (b) no digit was repeated in a given $S T$ set.

Three different 20 -word LT sets were selected. The Ss were divided into three equal groups and each group used one of the LT sets during all sessions. The first two and last two words were the same on each list and were tested only during warm-up trials. The middle 16 words of the lists were ordered randomly for each $S$ when presented for learning prior to the first test session.

Ten blocks of 32 trials each were constructed. Two blocks were used in the training session and eight were used in the two experimental sessions. Trial type probabilities within each block were as follows: Each of the ST set sizes (one to four) appeared with equal probability; both positive and negative trials appeared with equal probability; digit and word ST sets were given with equal probability; and, on positive trials, test probes were drawn from the ST and LT sets with equal probability. The location of positive test items within the ST sets was balanced across serial positions for each trial type. Each of the middle 16 words of the LT set was tested once during the two training blocks and twice during the four blocks of each experimental session.

Two additional blocks of eight trials each were constructed for use as warm-up trials. Each of the eight conditions tested in the training and experimental blocks appeared once in each warm-up block. One warm-up block was given at the start of each experimental session. One of the first two and one of the last two LT set words were tested in each warm-up block.

Except for test stimuli from the LT set (which varied with the LT set learned by a given S), all Ss received exactly the same words and digits as test stimuli. The trial blocks presented at each experimental session and the ordering of blocks within sessions, however, were systematically varied across Ss.

\section{Apparatus}

The ST sets for each trial were tape recorded and were presented through the speaker system of a manually operated recorder.

Each test stimulus was typed in capital letters on a white
$6 \times 9$ in. index card with an IBM Executive registry typewriter. The stimuli were presented in an Iconix tachistoscope (System 153). They appeared in the center of the visual field and subtended a horizontal visual angle of about $2 \mathrm{deg}$. A fixation target consisting of four dots in the shape of a rectangle was displayed at the center of the field for $0.5 \mathrm{sec}$ prior to the onset of the test stimulus on each trial. The display was dark between trials.

On a table to the S's right, three telegraph keys were arranged along an arc, with the centers of adjacent keys separated by about $3 \mathrm{~cm}$. The $S$ could comfortably rest her right forefinger on the center key between trials and could make short, natural movements to the left or right to strike either of the two response keys. Half of the Ss were randomly assigned the right key as the positive response and the left key as the negative response; the assignment was reversed for the other Ss. The S held in her left hand a button used to initiate display of the test stimulus on each trial.

\section{Procedure}

Each $\mathrm{S}$ was contacted by phone 12 to $48 \mathrm{~h}$ prior to the training session. One training and two experimental sessions were scheduled for 3 subsequent days. The $S$ was also given one of the LT sets and was told to memorize the list in the order given over the phone so that it could be recalled perfectly.

At the start of the training session, $S$ was required to write the LT set in correct serial order and then to recite the list in correct order. All Ss satisfied a criterion of correct written and oral recalls of the LT set. After S had completed both recalls successfully, she was seated at the tachistoscope and given instructions about the task. The $S$ was told that the experiment was designed to investigate how fast people can recognize words and digits they have learned. The $E$ explained that the experiment involved a series of test trials and that the following sequence would be followed on each trial: (a) E would start each trial by saying "ready;" (b) E would then turn on the tape recorder and $S$ would hear an ST set consisting of from one to four words or one to four one-digit numbers; (c) S would repeat the items in the ST set aloud once; (d) when S was ready, she was to push the start button in her left hand; (e) this would cause a fixation target to appear in the tachistoscope for $0.5 \mathrm{sec}$ and then a test stimulus would appear; (f) the test stimulus would remain visible until $S$ made a positive or negative response by pressing the appropriate key; (g) E would record the response time and a new trial would begin. It was explained that the positive set on each trial consisted of all words in the memorized list and the digits or words presented from the recorder on that trial. The S was told that each of the ST set words and each of the negative test words would be used on only one trial of the experiment. The instructions emphasized that $S$ was to respond as rapidly as possible while trying to avoid making errors. The two training blocks were then presented, with a short rest period between blocks. During testing Ss were told when they had made an error but not when they were correct. The time between trials was approximately $10 \mathrm{sec}$.

At the start of each of the experimental sessions, $S$ was again required to give both a written and an oral recall of the LT set she had learned. The instructions were then reviewed. One warm-up block and four test blocks were given during each experimental session. Each session lasted about $1 \mathrm{~h}$.

\section{RESULTS}

Table 1 presents a summary of the data collected during the two experimental sessions. The eight experimental conditions are labeled in the left-hand column of Table 1. The labels show the correct response ( $\mathrm{Y}$ for yes and $\mathrm{N}$ for no), then the type of test stimulus 
(D for digit. $W_{S}$ for an ST set word, $W_{L}$ for an LT set word, and $\mathrm{W}$ for a distractor word) and the type of ST set for each condition. The label $\mathrm{Y}\left(\mathrm{W}_{\mathrm{L}}\right.$, digits $)$, for example, indicates trials on which Ss gave a correct yes response to a test word from the LT set while the ST set contained digits: similarly, the label $\mathrm{N}(\mathrm{D}$,words) indicates trials on which Ss gave a correct no response to a test digit while the ST set contained words. The second column in Table 1 indicates the size of the ST set for each trial type.

A total of 144 observations were made for each of the 32 trial types. For each $S$, the mean RT for correct responses for each trial type was computed. Outlying scores for each $\mathbf{S}$ were eliminated from computations by the following method: (a) for each trial type, the mean was calculated; (b) each score that was more than 1.5 times greater than the mean was deleted; and (c) the mean was recalculated from the remaining scores. Approximately $3 \%$ of the scores were eliminated in this way. The mean and standard deviation of $S$ means for each trial type are presented in Columns 3 and 4 of Table 1. The last column presents the error rate for each trial type.

Table 1

RT Means for Correct Responses, Standard Deviations, and Error Rates for All Trial Types

\begin{tabular}{|c|c|c|c|c|}
\hline Condition & $\begin{array}{c}\text { ST Set } \\
\text { Size }\end{array}$ & $\begin{array}{l}\text { Mean } \\
(\mathrm{msec})\end{array}$ & $\begin{array}{c}\mathrm{SD} \\
(\mathrm{msec})\end{array}$ & $\begin{array}{c}\text { Percent } \\
\text { Errors }\end{array}$ \\
\hline $\mathrm{N}(\mathrm{D}$, Words) & $\begin{array}{l}1 \\
2 \\
3 \\
4\end{array}$ & $\begin{array}{l}626 \\
643 \\
619 \\
638\end{array}$ & $\begin{array}{l}156 \\
150 \\
132 \\
169\end{array}$ & $\begin{array}{l}0.7 \\
0.0 \\
0.7 \\
0.0\end{array}$ \\
\hline Y (D, Digits) & $\begin{array}{l}1 \\
2 \\
3 \\
4\end{array}$ & $\begin{array}{l}554 \\
612 \\
648 \\
645\end{array}$ & $\begin{array}{l}158 \\
179 \\
175 \\
209\end{array}$ & $\begin{array}{l}4.2 \\
2.7 \\
4.2 \\
3.5\end{array}$ \\
\hline N (D, Digits) & $\begin{array}{l}1 \\
2 \\
3 \\
4\end{array}$ & $\begin{array}{l}611 \\
651 \\
662 \\
680\end{array}$ & $\begin{array}{l}132 \\
164 \\
165 \\
131\end{array}$ & $\begin{array}{l}1.4 \\
2.7 \\
1.4 \\
0.7\end{array}$ \\
\hline $\mathrm{Y}\left(\mathrm{W}_{\mathrm{L}}\right.$, Digits $)$ & $\begin{array}{l}1 \\
2 \\
3 \\
4\end{array}$ & $\begin{array}{l}673 \\
666 \\
661 \\
680\end{array}$ & $\begin{array}{l}133 \\
125 \\
129 \\
120\end{array}$ & $\begin{array}{l}1.4 \\
2.1 \\
0.7 \\
2.1\end{array}$ \\
\hline N (W, Digits) & $\begin{array}{l}1 \\
2 \\
3 \\
4\end{array}$ & $\begin{array}{l}733 \\
766 \\
771 \\
777\end{array}$ & $\begin{array}{l}143 \\
169 \\
159 \\
170\end{array}$ & $\begin{array}{l}2.1 \\
2.7 \\
5.0 \\
4.2\end{array}$ \\
\hline$Y\left(W_{S}\right.$, Words $)$ & $\begin{array}{l}1 \\
2 \\
3 \\
4\end{array}$ & $\begin{array}{l}526 \\
596 \\
628 \\
641\end{array}$ & $\begin{array}{l}124 \\
156 \\
168 \\
184\end{array}$ & $\begin{array}{l}0.0 \\
2.1 \\
2.7 \\
2.7\end{array}$ \\
\hline$Y\left(W_{L}\right.$, Words $)$ & $\begin{array}{l}1 \\
2 \\
3 \\
4\end{array}$ & $\begin{array}{l}686 \\
675 \\
690 \\
695\end{array}$ & $\begin{array}{l}140 \\
114 \\
112 \\
113\end{array}$ & $\begin{array}{l}2.7 \\
2.7 \\
1.4 \\
1.4\end{array}$ \\
\hline$N($ W. Words) & $\begin{array}{l}1 \\
2 \\
3 \\
4\end{array}$ & $\begin{array}{l}713 \\
722 \\
725 \\
747\end{array}$ & $\begin{array}{l}136 \\
150 \\
151 \\
183\end{array}$ & $\begin{array}{l}3.5 \\
2.1 \\
2.7 \\
1.4\end{array}$ \\
\hline
\end{tabular}

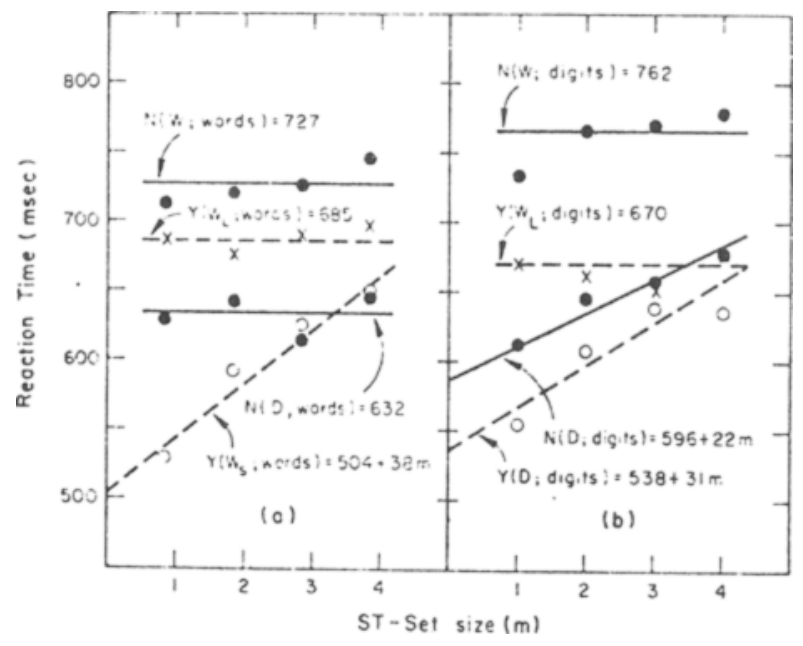

Fig. 1. Mean RT vs ST set size (a) for word sets and (b) for digit sets.

Separate analyses of variance were performed for each of the eight conditions using individual $\mathbf{S}$ means as scores. The effect of ST set size was significant only for the $Y(D$,digits $)$ condition $[F(3,51)=16.42, p<.01]$, the $\mathrm{N}(\mathrm{D}$,digits $)$ condition $[\mathrm{F}(3,51)=7.94, \mathrm{p}<.01]$, and the $\mathrm{Y}\left(\mathrm{W}_{\mathrm{S}}\right.$,words $)$ condition $[\mathrm{F}(3,51)=18.90, \mathrm{p}<.01]$. These three conditions were those in which a search of STM was sufficient to respond correctly. For the $\mathrm{N}(\mathrm{D}$,words) condition $[\mathrm{F}(3,51)=1.23, \mathrm{p}>.10]$, the $Y\left(\mathrm{~W}_{\mathrm{L}}\right.$, digits $)$ condition $[\mathrm{F}(3,51)=1.05, \mathrm{p}>.10]$, the $\mathrm{N}(\mathrm{W}$, digits) condition $[\mathrm{F}(3,51)=2.19, \mathrm{p}>.10]$, the $\mathrm{Y}\left(\mathrm{W}_{\mathrm{L}}\right.$, words $)$ condition $[\mathrm{F}(3,51)=1.12, \mathrm{p}>.10]$, and the $\mathrm{N}(\mathrm{W}$,words $)$ condition $[\mathrm{F}(3,51)=1.68, \mathrm{p}>.10], \mathrm{ST}$ set size had no effect on $R T$. The $Y\left(W_{L}\right.$,digits), $\mathrm{N}(\mathrm{W}$,digits $), \mathrm{Y}\left(\mathrm{W}_{\mathrm{L}}\right.$, words $)$, and $\mathrm{N}(\mathrm{W}$,words $)$ conditions were those in which a search of LTM was necessary to respond correctly, and the $\mathrm{N}(\mathrm{D}$,words) condition was the only one in which no search was required for a correct response.

Figures $1 \mathrm{a}$ and $\mathrm{lb}$ present the mean RT data for the word and digit ST set conditions, respectively. In both figures the data for each condition are plotted as a function of ST set size. Lines for the Y(D,digits), $\mathrm{N}\left(\mathrm{D}\right.$,digits), and $\mathrm{Y}\left(\mathrm{W}_{\mathrm{S}}\right.$, words) conditions were fit by the method of least squares, while lines for the other conditions were drawn at the mean RT computed over ST set sizes.

A paired $t$ test, using individual $S$ means averaged across the four ST set sizes, showed that the mean RT for the $N(W$,digits $)$ condition was significantly slower than the mean $\mathrm{RT}$ for the $\mathrm{N}(\mathrm{W}$,words) condition $[t(17)=4.03, p<.01]$. A similar $t$ test showed that the mean RT for the $Y\left(W_{L}\right.$, digits $)$ condition was faster than the mean $\mathrm{RT}$ for the $\mathrm{Y}\left(\mathrm{W}_{\mathrm{L}}\right.$, words $)$ condition $[\mathrm{t}(17)=2.32, \mathrm{p}<.05]$. Thus. Ss recognized test words from the LT set faster when the ST set contained digits than when it contained words. but they were slower in responding to distractor words when the ST set 
contained digits than when it contained words. A t test, using individual $\mathrm{S}$ means averaged across the four ST set sizes, showed that there was no significant difference between the mean RT for the $\mathrm{Y}\left(\mathrm{W}_{\mathrm{S}}\right.$,words) condition and the $Y(D$,digits $)$ condition $[t(17)=1.29, p>.10]$. Thus, there was no difference in the time required to recognize an ST set word and the time required to recognize an ST set digit.

As Table 1 indicates, the mean error rate for each of the experimental conditions was less than 5\%. ST set size had no systematic effect on error rate.

\section{DISCUSSION}

The first of the two hypotheses tested in the present experiment concerns the way STM and LTM are accessed in tasks that require a search of both stores. More specifically, the experiment was designed to test the predictions made by two simple models of how these stores might be accessed. The models to be considered are presented in Figs. 2 and 3. The model in Fig. 2 is a sequential model in which the search of one store is completed before the search of the other is begun. The ordering of the searches in Fig. 2 is consistent with the present results, which indicate that items from the ST set were recognized more quickly than were items from the LT set. The model presented in Fig. 3 is a parallel model in which STM and LTM can be accessed simultaneously.
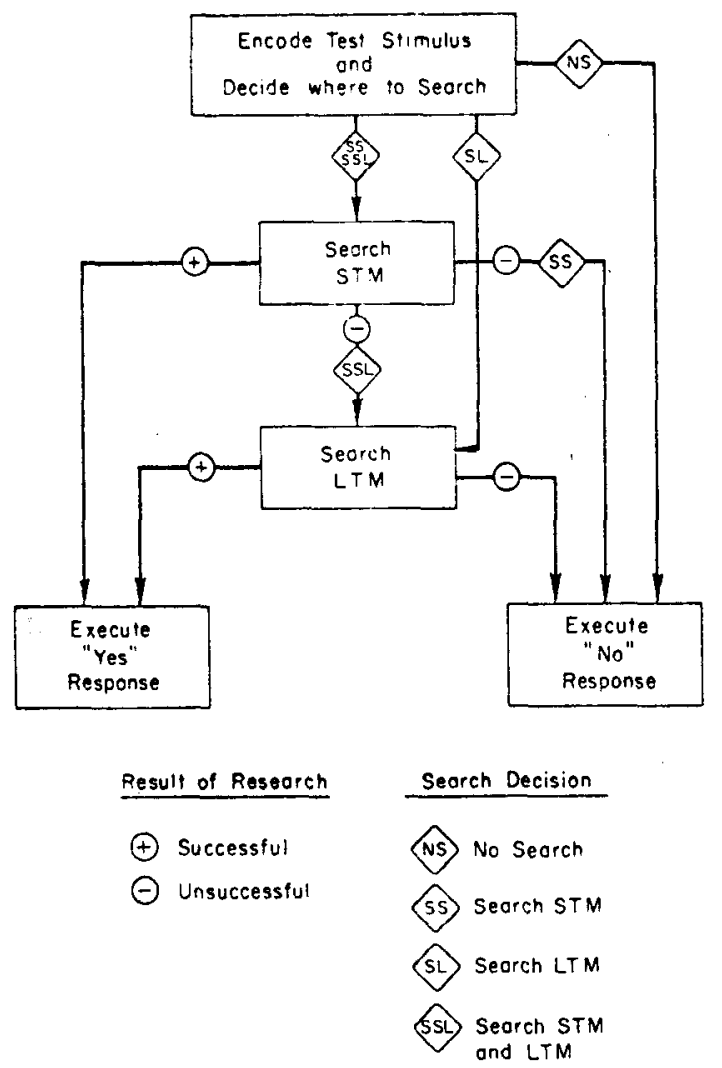

Fig. 2. Representation of a sequential access model.

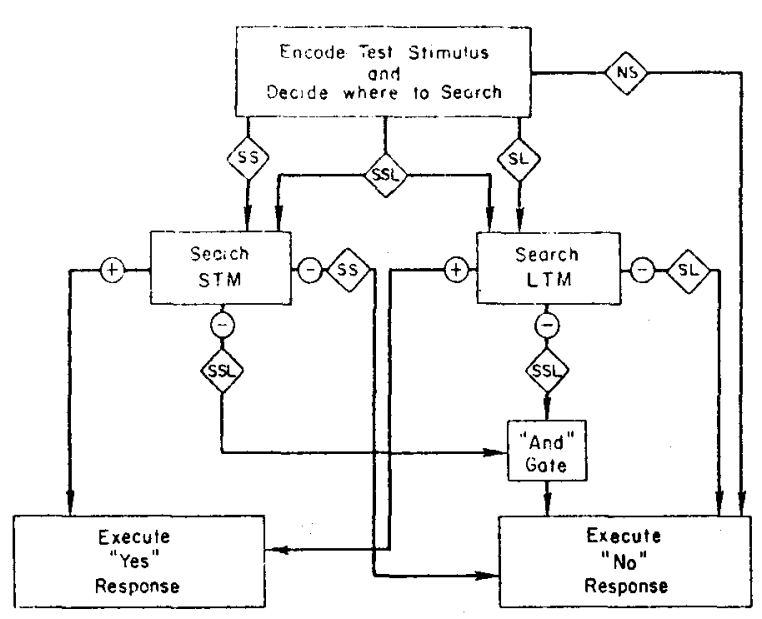

Fig. 3. Representation of a parallel access model. A key for the labels used in this figure is given in Fig. 2.

Both of the models presented above assume that $S$ encodes the test stimulus and decides whether to search STM, LTM, or both stores before any search is conducted. Although the present data do not provide a direct test of this assumption, it is certainly true that Ss must make such a decision if memory searches are to be at all systematic. It is further assumed in both models that $S$ decides to search a store only if it contains memory set items similar to the test probe. In the present experiment, then, the models assume that, when a word probe is presented, $\mathrm{S}$ always decides to search LTM but decides to search STM only if it contains words. When a digit probe is presented, $S$ never decides to search LTM and searches STM only if it contains digits.

An examination of the two models presented above shows that they make similar predictions for each of the first six experimental conditions presented in Table 1. For the N(D,words) condition, both models assume that $S$ decides not to make a search and immediately executes a no response (i.e., both stores contain words and the probe is a digit). Since no memory search is conducted, the models correctly predict that ST set size will have no effect on RT. For the $Y(D$,digits) condition and the N(D,digits) condition, both models assume that $S$ searches only STM and then executes either a yes or a no response. Since only STM is searched, the models correctly predict that ST set size will affect RT in these conditions. For the $\mathrm{Y}\left(\mathrm{W}_{\mathrm{L}}\right.$, digits) and the $\mathrm{N}(\mathrm{W}$,digits $)$ conditions, both models assume that $\mathrm{S}$ searches only LTM and then executes either a yes or a no response; here the models correctly predict no effect of ST set size, since STM is not searched.

The predictions for the $\mathrm{Y}\left(\mathrm{W}_{\mathrm{S}}\right.$,words $)$ condition are somewhat more complicated. For this condition, both models assume that $\mathrm{S}$ encodes the test stimulus and decides to search both stores. The parallel access model includes the equivalent of a logical "and" gate prior to the response stage, because when a decision to search both stores is made, a no response is executed only if both searches are unsuccessful. For the $\mathrm{Y}\left(\mathrm{W}_{\mathrm{S}}\right.$,words $)$ 
condition, then, the parallel model predicts that RT will not depend on the duration of the LTM search, because an unsuccessful LTM search produces only an output to the "and" gate. (The search of LTM must be unsuccessful, because the probe was never a member of the LT set in this condition.) The model correctly predicts that ST set size will affect RT because a yes response is executed immediately after the successful search of STM. The sequential access model assumes for this condition that $S$ begins to search STM first, after making the decision to search both stores. The model further assumes that, as in the parallel model, a yes response is executed immediately after the successful search of STM. Thus, both models correctly predict the ST set size effect for this condition.

For the $\mathrm{Y}\left(\mathrm{W}_{\mathrm{L}}\right.$,words $)$ condition and the $\mathrm{N}(\mathrm{W}$,words) condition, however, the two models make different predictions about the effect of ST set size on RT. The sequential model assumes that, for the $Y\left(W_{L}\right.$,words $)$ condition, S first searches STM, then searches LTM, and finally executes a yes response; for the $N(W$,words $)$ condition, S first searches STM, then searches LTM, and finally executes a no response. Total RT is predicted to be the sum of the times necessary to encode the test stimulus, search STM, search LTM, and execute either a yes or a no response. Since the time required to search STM is a function of the size of the ST set, total RT should be a function of the size of the ST set as well. This prediction of the sequential model is clearly inconsistent with the present results, since no ST set size effect was found for these conditions.

The parallel access model assumes that Ss access both stores simultaneously in the $Y\left(W_{L}\right.$,words $)$ and the $\mathrm{N}(\mathrm{W}$,words $)$ conditions. For the $\mathrm{Y}\left(\mathrm{W}_{\mathrm{L}}\right.$,words $)$ condition, the parallel model predicts that STM search time will have no effect on RT, because the unsuccessful search of STM produces only an output to the "and" gate. (The STM search must be unsuccessful because the probe was never a member of the ST set in this condition.) Since the time required to initiate the yes response does not depend on STM search time, the parallel model correctly predicts no ST set size effect for the $Y\left(W_{L}\right.$, words) condition. Furthermore, if the LTM search time is long relative to the STM search time, the model correctly predicts no ST set size effect for the N(W,words) condition as well. The model makes this prediction because, if the LTM search time is longer, the no response will be initiated at the end of the LTM search rather than at the end of the STM search. RTs to ST set words and LT set words suggest that the LTM search time was, in fact, longer than the STM search time in the present experiment. It should be noted that the results of the present experiment are similar to those reported by Wescourt and Atkinson (1973): both experiments support a simultaneous access model and are not consistent with a sequential access model.

Although the present results are not consistent with the simple sequential model presented in Fig. 2. models other than the one presented in Fig. 3 could be formulated to account for the present data. As Townsend (1971) has shown, it is often impossible to distinguish between unobservable serial and parallel processes by examination of input-output relationships. It is possible, for example, that a more complex model incorporating a probabilistic mixture of serial processes could account for the present data.

The second hypothesis tested by the present experiment concerns the relationship between the search processes in LTM and STM. More specifically, the experiment tested the hypothesis that the STM search has an effect on the LTM search. Here, as in the models presented in Figs. 2 and 3, it is assumed that Ss searched a memory store only if it contained items similar to the test probe. Given this assumption, a first test of the present hypothesis can be made by comparing the $\mathrm{Y}\left(\mathrm{W}_{\mathrm{L}}\right.$, words $)$ condition with the $\mathrm{Y}\left(\mathrm{W}_{\mathrm{L}}\right.$,digits $)$ condition; that is, these two conditions were identical except that the $Y\left(W_{L}\right.$,words $)$ condition involved a search of both memory stores, while the $\mathrm{Y}\left(\mathrm{W}_{\mathrm{L}}\right.$, digits $)$ condition involved a search of LTM only. The t test comparing RTs for these two conditions showed that Ss recognized LT set words more quickly when the ST set contained digits than when it contained words. A second test of this hypothesis can be made by comparing the $\mathrm{N}(\mathrm{W}$, digits) condition with the $\mathrm{N}(\mathrm{W}$,words) condition; these conditions both involved a search of LTM but differed in that the $\mathrm{N}(\mathrm{W}$,words) condition also involved a search of STM, while the $\mathrm{N}(\mathrm{W}$, digits $)$ condition did not. Again a t test showed a significant difference in RT for the two conditions. In this case, however, the difference was the reverse of the difference found for yes responses; Ss rejected distractor words more slowly when the ST set contained digits than when it contained words. Both of these comparisons indicate, then, that the contents of STM did affect the rate of search in LTM.

It should be noted that the RT differences discussed in the preceding paragraph are not easily explained in terms of encoding differences. It might have been argued, for example, that Ss encoded test words more quickly on trials with word ST sets because word probes were more likely to be presented on those trials than on trials with digit ST sets. Such a hypothesis could explain the difference between the $\mathrm{N}(\mathrm{W}$,words) and the $\mathrm{N}(\mathrm{W}$, digits) conditions but could not account for the fact that $R T$ for the $Y\left(W_{L}\right.$,words $)$ condition was slower than $R T$ for the $Y\left(W_{L}\right.$,digits $)$ condition. Although the probability distribution of test stimuli may have affected encoding times slightly for these conditions, the RT differences discussed above seem primarily to reflect a change in the way LTM is searched. It should also be noted that the parallel access model presented in Fig. 3 cannot account for these RT differences without additional assumptions about the nature of the LTM search. The criterion shift discussed by Atkinson and Juola (1973, in press) in their model of recognition memory is one mechanism that might account for this change. since it produces both faster yes responses and 
slower no responses. The present data, however, provide no direct test of the assumptions of that model.

One final result not suggested by the model presented in Fig. 3 concerns the $N(D$,words) condition. As indicated in Fig. 1, this condition (which presumably required no memory search) had a slower mean RT than did the fastest RT for the N(D,digits) condition (which did require a search of STM). As was suggested above and as previous studies (e.g., Kreuger, 1970) have shown, RT decreases for more frequent test stimuli. In the present experiment, the probability of a digit test stimulus was .25 given an ST set composed of words but .50 given an ST set composed of digits. It may have been, then, that Ss were more prepared to process a digit test stimulus in the N(D,digits) condition than in the $\mathrm{N}(\mathrm{D}$,words) condition.

\section{REFERENCES}

Atkinson, R. C., \& Juola, J. F. Factors influencing speed and accuracy of word recognition. In S. Kornblum (Ed.), Attention and performance $I V$. New York: Academic Press, 1973.
Atkinson, R. C., \& Juola, J. F. Search and decision processes in recognition memory. In D. H. Krantz, R. C. Atkinson, R. D. Luce, and P. Suppes (Eds.), Contemporary developments in mathematical psychology. San Francisco: Freeman, in press.

Juola, J. F., Fischler, 1., Wood, C. T., \& Atkinson, R. C. Recognition time for information stored in long-term memory. Perception \& Psychophysics, 1971, 10, 8-14.

Kreuger, L. E. Effect of stimulus probability on two-choice reaction time. Journal of Experimental Psychology, 1970, 84, 377-379.

Sternberg, S. Memory scanning: Mental processes revealed by reaction-time experiments. American Scientist, 1969, 57, 421.457.

Townsend, J. T. A note on the identifiability of parallel and serial processes. Perception \& Psychophysics, 1971, 10, 161-163.

Wescourt, K. T., \& Atkinson, R. C. Scanning for information in long- and short-term memory. Journal of Experimental Psychology, 1973, in press.

(Received for publication January 15, 1973; revision received April 12, 1973.) 